\title{
Can bilirubin/albumin ratio predict neurodevelopmental outcome in severe neonatal hyperbilirubinemia? A 3-month follow up study
}

Reem M. Soliman * D, Iman F. Iskander, Esraa A. Elmazzahy and May A. K. Abdellatif

\begin{abstract}
Background: The risk of kernicterus and BIND may be in part determined by total serum bilirubin (TSB) and by the level of non-albumin bound free bilirubin, which can easily pass the blood-brain barrier. Free bilirubin (Bf) seems a more reliable predictor for bilirubin neurotoxicity. Bilirubin/albumin ratio $(B / A)$ is considered a surrogate parameter for Bf and has been more useful than TSB. The aim of the study is to determine whether B/A ratio correlates with $B I N D$ in newborns with severe hyperbilirubinemia and if it can predict poor neurologic outcome at 3 months follow up.

Results: This prospective study included one hundred seventeen outborn neonates $\geq 35$ weeks admitted in a tertiary care neonatal intensive care unit, between May and December 2012, with TSB $\geq 20$ mg/dl or necessitating exchange transfusion. Total serum bilirubin and serum albumin were done on admission and bilirubin/albumin ratio was calculated. BIND score was calculated. At the age of 3 months, 112 neonates were followed up with a detailed neurological assessment. Babies who depicted any abnormal motor examination were subjected to brain stem auditory evoked response and MRI examination. Seven infants (6.2\%) presented with kernicterus on follow up. BIND scores on admission, mean TSB, and bilirubin/albumin ratio was significantly higher in kernicteric infants compared with those having normal neurological outcome at 3 months of age (P 0.001). The lowest TSB level at which kernicterus occurred in our study was $31 \mathrm{mg} / \mathrm{dl}$. Receiver operation characteristics analysis identified B/A ratio cut off value for predicting kernicterus of 9.6 with sensitivity of $100 \%$ and specificity of $91.4 \%$, whereas TSB cut off value of $30 \mathrm{mg} / \mathrm{dl}$ showed sensitivity of $100 \%$ and specificity of $83 \%$.
\end{abstract}

Conclusion: B/A ratio is a strong indicator for the risk of kernicterus. B/A is more specific than TSB and should be used in the early management of neonatal hyperbilirubinemia.

Keywords: Neonatal jaundice, B/A ratio, Kernicterus

\footnotetext{
* Correspondence: mahmoudreem@rocketmail.com

Department of Pediatrics Faculty of Medicine, Cairo University, Cairo, Egypt
}

\section{Springer Open}

(ㅇ The Author(s). 2021 Open Access This article is licensed under a Creative Commons Attribution 4.0 International License, which permits use, sharing, adaptation, distribution and reproduction in any medium or format, as long as you give appropriate credit to the original author(s) and the source, provide a link to the Creative Commons licence, and indicate if changes were made. The images or other third party material in this article are included in the article's Creative Commons licence, unless indicated otherwise in a credit line to the material. If material is not included in the article's Creative Commons licence and your intended use is not permitted by statutory regulation or exceeds the permitted use, you will need to obtain permission directly from the copyright holder. To view a copy of this licence, visit http://creativecommons.org/licenses/by/4.0/. 


\section{Background}

Approximately $60-70 \%$ of term infants develop jaundice in the first week of life [1]. Syndrome of bilirubininduced neurologic dysfunction (BIND) represents a spectrum of neurologic manifestations among vulnerable infants who have experienced an exposure to bilirubin. Clinical neuro motor manifestations extend from a range of subtle processing disorders with objective disturbances of vision, motor power, hearing, speech, cognition, and language among infants with history of moderate to severe hyperbilirubinemia [2].

Clinical signs of acute bilirubin encephalopathy (ABE) were reported by Van Praagh [3] and Volpe [4]. Johnson et al. [5] designed bilirubin encephalopathy into a 9point bilirubin-induced neurologic dysfunction (BIND) score assessing mental status, muscle tone, and cry patterns (Table 1). A BIND score of 0 is normal, whereas BIND scores $1-3,4-6$, and 7-9 were assigned to represent mild, moderate, and severe $\mathrm{ABE}$, respectively; they also proposed that the BIND score could predict long term outcome [6].

American Academy of Pediatrics (APP) guidelines for the management of neonatal hyperbilirubinemia are based on the assumption that total serum bilirubin (TSB) is the most important predictor for bilirubin encephalopathy [7]. The risk of kernicterus and BIND may be in part determined by TSB and also by the level of non-albumin bound free bilirubin (Bf), which can easily pass the blood-brain barrier and thus better reflects the bilirubin load distributed in the brain [8]. Compared with TSB, free bilirubin (Bf) seems a more reliable predictor for bilirubin neurotoxicity as assessed by auditory brainstem response (ABR) maturation and electroencephalography and to correlate better with kernicterus [9].

Unfortunately clinical laboratory measurements of $\mathrm{Bf}$ are not available. Bilirubin/albumin ratio $(\mathrm{B} / \mathrm{A})$ is considered a surrogate parameter for $\mathrm{Bf}$ and has been more useful than TSB alone to indicate the Bf concentration and predicts neurotoxicity [10]. It is recommended as a safe-guard to identify the rare infant at risk for neurotoxicity at low TSB because of a low serum albumin concentration. Clinical evidence comparing the relationships of TSB and $B / A$ ratio with outcome is sparse [11].

The aim of the study is to determine whether B/A ratio correlates with BIND in newborns with severe hyperbilirubinemia and can predict poor neurologic outcome at 3 months follow up.

\section{Methods \\ Patients}

One hundred seventeen outborn neonates admitted to NICU, an academic tertiary care referral center, were enrolled in this prospective cohort study between May and December 2012. Enrollment criteria included infants with estimated gestational age $\geq 35$ weeks; who developed jaundice in the first 7 days of life and having TSB $\geq 20 \mathrm{mg} / \mathrm{dl}$ or necessitating exchange transfusion according to recommendations of the AAP guidelines for management of neonatal jaundice [7]. Babies suffering from direct hyperbilirubinemia, perinatal asphyxia, CNS malformations,

Table 1 BIND score [5]

\begin{tabular}{|c|c|}
\hline Scores & Clinical signs \\
\hline \multicolumn{2}{|c|}{ Mental status } \\
\hline 0 & Normal \\
\hline 1 & Sleepy, poor feeding \\
\hline 2 & Lethargic, irritable, jittery \\
\hline 3 & Unable to feed, apnea, seizures, coma \\
\hline \multicolumn{2}{|l|}{ Muscle tone } \\
\hline 0 & Normal flexed tone (awake) \\
\hline 1 & Hypertonia alternating with hypotonia \\
\hline 2 & Neck stiffness, flexor spasm, beginning of neck and back arching, hypertonia \\
\hline 3 & Persistent retrocollis and opisthotonos, bicycling, twitching of hands and feet, fisting, severe hypotonia with limp posture \\
\hline \multicolumn{2}{|l|}{ Cry pattern } \\
\hline 0 & Normal \\
\hline 1 & High pitched cry \\
\hline 2 & Shrill cry even if intermittent \\
\hline 3 & Weak or absent cry, inconsolable cry \\
\hline Total score & Sum of highest score in each category \\
\hline
\end{tabular}

Scores 1-3: mild $A B E ;$ probably reversible without sequelae

Scores 4-6: moderate ABE

Scores 7-9: severe ABE; highly associated with death or kernicterus 
or hemodynamically unstable were excluded. The study protocol was approved by the ethical board and written informed consent was obtained from parents after NICU admission.

Apgar scores and birth weight could not be accurately documented since all babies were outborn and not attending regular post discharge follow up; admission weight was used instead.

Detailed neurological examinations focusing on signs of BIND was done by two independent researchers; at admission time, repeated after $6 \mathrm{~h}$ with the first follow up of serum bilirubin and again before discharge; findings were recorded on a checklist showing items of BIND score [5] (Table 1); then audited and score calculated by third researcher. Researchers performing initial and follow up neurological examination and calculating the BIND score were blinded to laboratory data and not involved in the patients' management. BIND score of $1-3$ represents mild $\mathrm{ABE}$ : probably reversible without sequelae; scores 4-6: moderate ABE; and scores 7-9: severe ABE; highly associated with death or kernicterus [12].

\section{Laboratory workup}

Total serum bilirubin and serum albumin were done on admission and bilirubin/albumin ratio was calculated. TSB was measured [13]. TSB was followed up after $6 \mathrm{~h}$. Hemoglobin, hematocrit levels, and reticulocytic count were recorded. Blood group of mothers and babies together with direct Coomb's test were performed.

\section{Follow up at 3 months}

One hundred twelve neonates were followed up at the age of 3 months. Five babies were lost for follow up. Babies underwent detailed neurological assessment including (a) muscle tone of trunk, upper, and lower limbs; (b)reflexes including deep tendon reflexes, primitive neonatal reflexes (Moro, suckling, and tonic neck reflexes), extrapyramidal reflexes (cremasteric and abdominal reflexes); and (c) neurodevelopmental assessment including head control, social smile, response to sound, and eye contact. Babies who depicted any abnormal motor examination were subjected to brain stem auditory evoked response (BAER) and magnetic resonance imaging (MRI). Infants were diagnosed as having kernicterus if two of the following three are present, with one being an abnormality of muscle tone; abnormal MRI with the specific abnormality in the globus pallidus and/ or the subthalamic nucleus and abnormal ABR auditory brain stem response [14].

\section{Statistics}

Numerical data are expressed as arithmetic mean \pm SD and median (25th-75th). Inter-groups comparisons were done using Mann-Whitney test. Qualitative data were presented as number (percent) and compared using Chisquare $\left(X^{2}\right)$ test or Fisher's exact test as appropriate. To assess the clinical potential of bilirubin/albumin ratio for outcome, normal versus kernicterus receiver operating characteristic (ROC) curves were plotted, and the area under curves (AUC) were calculated [15]. Sensitivity, specificity, PPV, NPV, and accuracy were evaluated at specified cutoff levels. Statistical analysis was run on SPSS for windows release 17 (SPSS Inc., Chicago III, USA). $P$ values $<0.05$ were considered statistically significant.

\section{Results}

Two hundred ninety-six neonates were admitted to NICU during a period of 3 months; of them, 117 (39.5\%) neonates $\geq 35$ weeks and suffering from severe hyperbilirubinemia $(\geq 20 \mathrm{mg} / \mathrm{dl})$ or necessitating exchange transfusion according to AAP guidelines were enrolled in the study. Male predominance was reported among the studied population, with male to female ratio of 1.4: 1. Mean gestational age of enrolled newborns was 37.8 weeks; birth weight was not known in most babies and New Ballard score cannot be done since many enrolled newborns were first seen past $48 \mathrm{~h}$ of life; hence, admission weight was used as surrogate parameter for maturation. Their mean weight on admission was $2.9 \mathrm{~kg}$. Mean onset of jaundice was 2.9 days of life, and mean age of NICU admission was 5.5 days old. Mean TSB and bilirubin/albumin ratio of the studied population on admission was $26.15 \pm 6 \mathrm{mg} / \mathrm{dl}$ and $7.7 \pm 1.9$ respectively. Table 2 reveals the characteristics of the whole study population and admission TSB.

Hemolysis accounted for $42 \%$ of etiologies of hyperbilirubinemia in enrolled newborns; $29.9 \%$ and $7.6 \%$ due to $\mathrm{ABO}$ and $\mathrm{RH}$ incompatibility respectively. While undiagnosed hemolytic causes represented $4.2 \%$; may be attributed to minor group incompatibilities which are not routinely tested. Fifty-six percent of infants had no identifiable cause of jaundice.

Acute bilirubin encephalopathy (ABE) was found in $13.6 \%$ of the studied babies on admission. According to their BIND scores, twelve babies (10\%) had subtle ABE; 3 newborns (2.5\%) had moderate $\mathrm{ABE}$ while only one patient $(0.8 \%)$ had advanced $\mathrm{ABE}$.

Patients were managed according to our unit protocol based on the recommendations of the AAP for the management of severe neonatal jaundice [7]. All patients were treated with phototherapy; 18 (15.4\%) neonates had exchange transfusion including all patients admitted with ABE (bind scores 2-9).

\section{Neurologic outcome at 3 months}

One hundred twelve infants returned for follow up at 3 months of age and underwent neurological assessment; 
Table 2 Demographic and laboratory data of the studied population $(n=117)$

\begin{tabular}{ll}
\hline Characteristics & \\
\hline Male & $70(59.8 \%)$ \\
Gestational age (weeks) & $37.8 \pm 0.6$ \\
Weight (g) & $2906 \pm 443$ \\
Maternal diabetes & $4(3.4 \%)$ \\
Onset of jaundice (days) & $2.9 \pm 1.35$ \\
Age at admission (days) & $5.52 \pm 2.7$ \\
Bilirubin on admission (mg/dl) & $25(22-28.7)$ \\
Albumin on admission (g/dl) & $3.4(3.2-3.4)$ \\
Bilirubin/albumin ratio (mg/dl) & $7.3(6.4-8.9)$ \\
Reticulocyte count \% & $4.2(1.7-12)$ \\
Positive Coombs test & $34(40 \%)$ \\
Rh Incompatibility & $9(7.69 \%)$ \\
ABO Incompatibility & $35(29.9 \%)$ \\
Suspected Sepsis & $2(1.7 \%)$ \\
BIND score on admission & \\
0-3 & 113 \\
4-7 & 4 \\
Conventional (double) phototherapy & $105(89.7 \%)$ \\
Intensive phototherapy & $7(6 \%)$ \\
Exchange transfusion & $5(4.3 \%)$ \\
BIND score on discharge & $10(8.5 \%)$ \\
4-7 (ABE) & $107(91.5 \%)$ \\
Neurological outcome at 3 months & $16.4 \%)$ \\
\hline & \\
Nernissed follow up & \\
\hline
\end{tabular}

Sepsis was suspected if there were clinical signs of sepsis associated with positive blood culture OR 2 of the following (a) elevated CRP, (b) total leucocytic count $>25,000$ or $<5000$, (c) immature to total neutrophil of ratio $>$ 0.2 , and (d) band count $>10 \%$

5 infants missed follow up. Seven infants (6.2\%) presented with kernicterus on follow up. All 7 babies did not have head support and had hypertonia; six could not respond to sound and three had choreoathetosis. Four of the seven developed social smile and four had eye contact. MRI and BAER were done for all babies with abnormal motor examination; all MRI came normal and none showed globus pallidus affection. Six infants had severe to profound auditory impairment detected in their BAER. One kernicteric patient died at age of 5 months; cause of death is unknown.

The kernicteric group showed male predominance (57\%). Of the seven kernicteric patients, one had RH incompatibility, two had ABO hemolytic disease, and 4 suffered from non-hemolytic jaundice. All kernicteric babies received intensive phototherapy and all had exchange transfusions.

Regarding BIND scores on admission of the kernicteric babies, one had advanced ABE (BIND score 7), 3 had moderate $\mathrm{ABE}$ (BIND score of 4,5 , and 6 ), while the remaining 3 patients had mild $A B E$ (BIND score 1, 2, and 3). One of them had moderate ABE (BIND score 4) and 6 had mild ABE (BIND score 1-3) on discharge. All infants with zero BIND scores on admission were normal on follow up. All babies with BIND score $\geq 4$ had neurological sequelae at 3 months of age. BIND scores on admission were significantly higher in kernicteric infants compared to infants with normal neurological outcome at 3 months of age (P 0.001) (Table 3).

Newborns with normal BIND score on admission had significantly lower bilirubin albumin ratio $(7.5 \pm 1.7)$ than newborn with severe ABE (BIND 4-7) $(11.8 \pm 1.3)$ $(P 0.000)$.

Ten $(41.6 \%)$ of 24 infants with TSB $\geq 30 \mathrm{mg} / \mathrm{dl}$ showed ABE; three resolved with treatment, while 7 (29\%) developed kernicterus. The lowest TSB level at which kernicterus occurred in our study was $31 \mathrm{mg} / \mathrm{dl}$. Although five neonates with $\mathrm{TSB}<30 \mathrm{mg} / \mathrm{dl}$ developed subtle $\mathrm{ABE}$ (BIND SCORE 0-1), none of them developed permanent neurological sequelae and all were normal at the time of follow up. TSB and B/A ratio on admission were significantly higher in all kernicteric patients compared to other jaundiced babies with normal neurologic outcome on follow up (P 0.001) (Table 4).

Receiver operation characteristics (ROC) analysis identified $\mathrm{B} / \mathrm{A}$ ratio cutoff value for predicting kernicterus of 9.6 (AUC 0.977 ) with sensitivity of $100 \%$, specificity of $91.4 \%$, and accuracy of $92 \%$ (Fig. 1, Table 5), whereas TSB cutoff value of $30 \mathrm{mg} / \mathrm{dl}$ showed sensitivity of $100 \%$ and specificity of $83 \%$.

\section{Discussion}

In this prospective observational trial, we found that BIND scores on admission, TSB, and B/A ratio were significantly higher in kernicteric infants compared to other jaundiced infants with normal neurological outcome at 3 months of age. A B/A ratio of 9.6 had sensitivity of $100 \%$ and specificity of $91 \%$ for predicting poor neurologic outcome at 3 months of age. B/A ratio was more specific than TSB in the prediction of poor neurologic outcome.

Regardless of the cause for jaundice, there is a risk of neonatal bilirubin neurotoxic sequelae that ranges from irreversible permanent injury to subtle multisensory and learning impairments during infancy. Confounding effects of prematurity, hemolysis, altered bilirubin-albumin binding, severity of bilirubin exposure, and the individual vulnerability of the infant contribute to the spectrum of 
Table 3 BIND score, serum bilirubin, and bilirubin albumin ratio

\begin{tabular}{llll}
\hline BIND score on admission & Total serum bilirubin $(\mathbf{m g} / \mathbf{d l})$ & Bilirubin albumin ratio & Kernicterus \\
\hline$(0)$ & $24.9 \pm 4.2$ & $7.3 \pm 1.4$ & None \\
$(1-3)$ & $31.3 \pm 6.8$ & $9.8 \pm 2.6$ & 3 \\
$(4-7)$ & $40.1 \pm 4.2$ & $11.8 \pm 1.3$ & 4 \\
BIND score on discharge & & & 6 \\
$(1-3)$ & & & $1 / 1$ \\
$(4-7)$ & & & \\
\hline
\end{tabular}

clinical manifestations to be designated as syndrome of BIND [2].

Jaundice due to hemolysis is usually severe and appears within the first $24 \mathrm{~h}$. Sgro et al. considered presentation within the first $48 \mathrm{~h}$ of age a strong predictor of abnormal neurological outcome in infants with severe neonatal hyperbilirubinemia [16]. On the contrary, we did not find any significant difference between ages of onset of jaundice among kernicteric infants compared with those having normal neurologic outcome.

In the current study, we reported $\mathrm{ABE}$ in $13 \%$ of our studied population. Nearly all infants who had residual neurologic deficits at 3 months follow up had BIND scores $\geq 4$ on admission. Although babies with BIND score $0-1$ should be completely normal at follow up [2], in the present study all but one baby were normal. This specific case had a BIND score of 1 on admission and a BIND score of 2 on discharge and had persistent neurologic affection on the 3 month follow up. He was diagnosed as Rh incompatibility, had serum bilirubin level of $41 \mathrm{mg} / \mathrm{dl}$, and had the highest B/A (13.6) ratio among the kernicteric patients. Gamaleldin et a [17]. reported $40 \%$ of their cases suffered from $A B E$ on admission; higher percentage than our results. This higher incidence of $A B E$ could be explained by their inclusion criteria which required a higher admission TSB (> $25 \mathrm{mg} / \mathrm{dl})$.

The lowest TSB level at which kernicterus occurred in our study was $31 \mathrm{mg} / \mathrm{dl}$. Consistent with our results, Iskander et al. [11] reported that asymptomatic term newborns without risk factors rarely develop kernicterus or auditory neuropathy at TSB $<31 \mathrm{mg} \%$ and/or B/A < $8.6 \mathrm{mg} / \mathrm{g}$ and recommended that given the risks of exchange transfusion [18] and intensive phototherapy and close monitoring may be a safer treatment option for those infants. Mukhopadhyay et al. [19] found that all kernicteric babies in their study had TSB $>30 \mathrm{mg} / \mathrm{dl}$ as well. Analysis of this cumulative evidence may be used to revise the guidelines as to whether the cut off level at which exchange transfusion should be performed can be higher than $25 \mathrm{mg} / \mathrm{dl}$ among healthy full term neonates.

Johnson et al. [6] suggested that any infant with TSB $>35 \mathrm{mg} / \mathrm{dl}$ had post icteric sequelae regardless of age and intervention. However in the present study, 9 babies had TSB > $35 \mathrm{mg} / \mathrm{dl}$ of whom 6 patients $(66.6 \%)$ had kernicterus and three appeared normal at 3 months follow up. Shapiro [14] reported that subtle neurotoxicity may appear later or even at school age as learning disabilities. This could be the case with these three newborns making long term follow up a necessity. It is clear from the previous results that there exists a wide variation in the individual response to TSB which indicates that though serum bilirubin is sensitive yet it is not specific. This also indicates that the pathogenesis of $\mathrm{BE}$ involves critical plasma and/or host defense variables that have to be identified.

Oh et al. [20] found that higher Bf levels are associated with a higher risk of death or adverse neurodevelopmental outcome regardless of clinical status. In the absence of an available assay for $\mathrm{Bf}$, the bilirubin/albumin ratio $(\mathrm{B} / \mathrm{A})$ might provide a better estimate of $\mathrm{Bf}$ because it contains two of the three factors determining Bf: TSB, albumin, and the albumin-binding affinity [21]. However, due to the presence of drugs that interfere with bilirubin binding to albumin, and variations in the intrinsic affinity of albumin binding to bilirubin, $\mathrm{Bf}$ may be much higher than suggested by the calculated $\mathrm{B} / \mathrm{A}$ ratio [22].

Considering the occurrence of bilirubin encephalopathy in preterm infants with low TSB levels, the risk of developing bilirubin neurotoxicity is not determined by TSB alone [23]. Only free bilirubin and perhaps the B/A ratio are more closely associated with BIND. Authors conclude that the pathophysiological role of low serum

Table 4 Comparison of poor neurologic outcome, TSB, B/A ratio, and BIND scores on admission

\begin{tabular}{llll}
\hline & Normal infants & Kernicteric infants & $P$ value \\
\hline Total serum bilirubin & $25 \pm 4.4$ & $38.8 \pm 4.5$ & 0.001 \\
Bilirubin albumin ratio & $7.42 \pm 1.48$ & $11.7 \pm 1.49$ & 0.001 \\
BIND score on admission & $0.08 \pm 0.3$ & $3.8 \pm 2$ & 0.001 \\
\hline
\end{tabular}

$P$ value $<0.05$ is considered significant 


\section{ROC Curve}

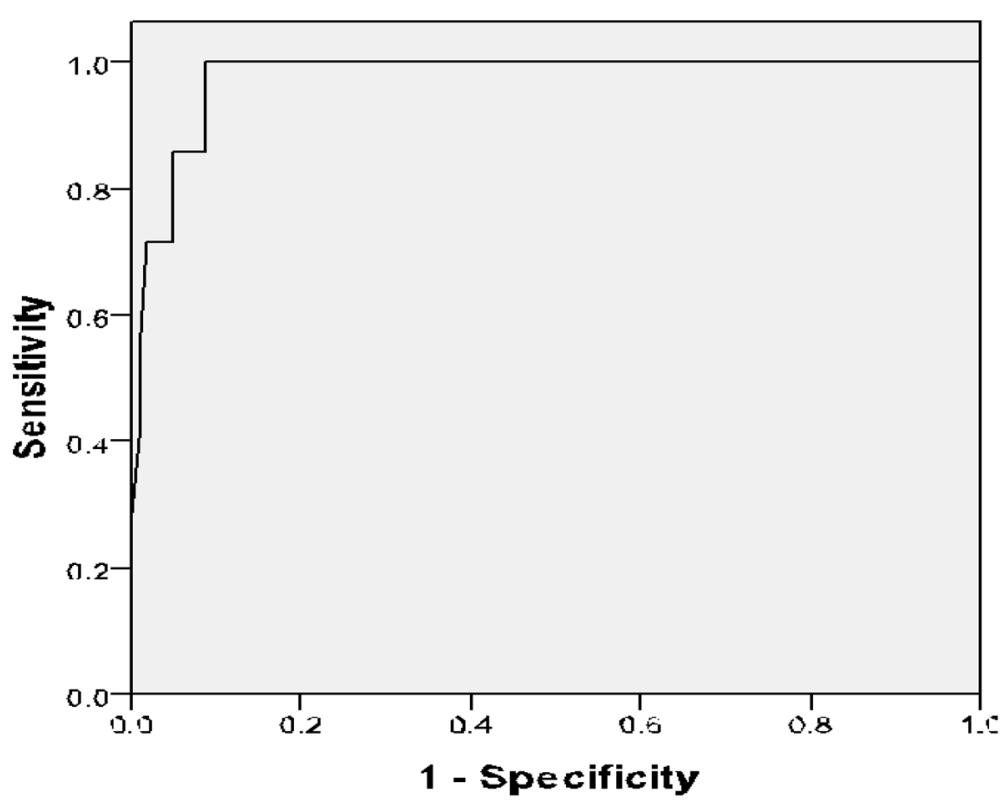

Diagonal segments are produced by ties.

Fig. 1 ROC curve for B/A ratio. The ROC curve shows that a B/A ratio of 9.6 was 100\% sensitive and $91.4 \%$ specific and $92 \%$ accurate to detect poor neurologic outcome in neonates suffering from severe neonatal hyperbilirubinemia at 3 months of age

albumin levels must be considered in BIND especially when acidosis and jaundice are present in preterm infants [24]. Severe hemolytic disease and capillary leak from a variety of conditions can result in plasma albumin depletion. In such infants, the risk for kernicterus may occur at TSB levels well below AAP-recommended intervention levels for sick infants, but the B/A cutoff would be breeched [25].

Several experts in the field of bilirubin research advocate the additional use of $\mathrm{B} / \mathrm{A}$ ratio in jaundiced infants especially when TSB level is close to that at which exchange transfusion is recommended; that is next to but not instead of TSB, on which to base the management of hyperbilirubinemia [26, 27].
Ardakani et al. [28] reported a mean B/A ratio of $10 \pm$ 1.6 among his studied neonates presenting with $\mathrm{BE}$. He identified B/A of 8 to predict acute BIND (AUC 0.957) with sensitivity of $100 \%$ and specificity of $66 \%$, whereas a TSB cut off value of $25 \mathrm{mg} / \mathrm{dl}$ showed sensitivity of $100 \%$ and specificity of $57 \%$; hence, agreeing with our results that $\mathrm{B} / \mathrm{A}$ ratio was more specific than TSB in the prediction of poor neurologic outcome.

In their randomized controlled study, Hulzbos et al. [10] concluded that they did not find any significant effect of the additional use of $\mathrm{B} / \mathrm{A}$ ratio compared to TSBbased treatment on the motor development in preterm babies at 2 years of life; however, they reported significantly higher $\mathrm{B} / \mathrm{A}$ ratios in their non survivors. They speculated that the additional use of $\mathrm{B} / \mathrm{A}$ ratio is a

Table 5 Sensitivity and specificity for cut offs predicting poor neurological outcome

\begin{tabular}{|c|c|c|c|c|c|c|}
\hline \multirow[t]{3}{*}{ Cut off value } & \multirow{2}{*}{\multicolumn{2}{|c|}{$\frac{\mathrm{B} / \mathrm{A} \text { ratio }}{9.6}$}} & \multicolumn{4}{|l|}{ TSB } \\
\hline & & & \multicolumn{2}{|l|}{$25 \mathrm{mg} / \mathrm{dl}$} & \multicolumn{2}{|l|}{$30 \mathrm{mg} / \mathrm{dl}$} \\
\hline & Affected & Normal & Affected & Normal & Affected & Normal \\
\hline Test positive & 7 & 9 & 7 & 45 & 7 & 17 \\
\hline Test negative & 0 & 96 & 0 & 60 & 0 & 88 \\
\hline Sensitivity & \multicolumn{2}{|l|}{$100 \%$} & \multicolumn{2}{|l|}{$100 \%$} & \multicolumn{2}{|l|}{$100 \%$} \\
\hline Specificity & \multicolumn{2}{|l|}{$91.4 \%$} & \multicolumn{2}{|l|}{$57 \%$} & \multicolumn{2}{|l|}{$83.3 \%$} \\
\hline
\end{tabular}


valuable parameter in the management of hyperbilirubinemia in preterm infants when the bilirubin is more harmful and the infant brain is more vulnerable to bilirubin neurotoxicity.

In their cohort of 193 term infants, Iskander et al. [11] reported that moderate to severe bilirubin encephalopathy occurred only when the molar concentration of bilirubin approached or surpassed the concentration of albumin at $\mathrm{B} / \mathrm{A}$ ratio of $8.8 \mathrm{mg} / \mathrm{dl}$. As TSB exceeds this binding capacity, free bilirubin increases dramatically and the final deposition is governed by the availability of alternative plasma binding loci and ultimately by the low solubility of free bilirubin. In the present study, all babies with $\mathrm{B} / \mathrm{A}$ ratio $>13 \mathrm{mg} / \mathrm{g}$ developed kernicterus. However, we observed one baby with normal outcome at B/A ratio of $12.7 \mathrm{mg} / \mathrm{g}$. This suggests that additional bilirubin binding sites other than albumin must exist in plasma. They partly agreed with our results that B/A ratio at cut off 11.5 is a strong predictor for residual bilirubin neurotoxicity with $100 \%$ sensitivity but they stated that B/A offers no additional advantage over TSB alone.

Despite the fact that no definite cut off value at which TSB or B/A ratio are neurotoxic is yet known, we therefore agree with Johnson and Bhutani [2] that it is very important to study and identify the individual variations in the ability to buffer bilirubin the brain and the factors that expedite or delay its neuronal exit which may render the baby more prone to neurological insults thus preventing kernicterus.

ElTatawy and colleagues [29] confirmed that a cut off TSB $\geq 27.5 \mathrm{mg} / \mathrm{dl}$ was found to detect kernicterus and auditory impairment at 1 year of age (100\% sensitive, $76 \%$ specific). They found that poor neurodevelopmental outcome as well as auditory impairment was positively correlated to high TSB, high BIND score, and longer duration of exposure to severe hyperbilirubinemia. They reported that $41 \%$ of the studied population had unfavorable outcomes at 3 months of age and further reduced to $13.6 \%$ at 1 year of age since most of them improved with time. These numbers were much higher than our results in which only $6 \%$ of enrolled neonates presented with kernicterus at 3 months follow up. We attributed this difference to different methods of neurological evaluation at follow up visits.

Limitations of this study include absence of risk stratification, gestational age, and cause of jaundice was not clear in some included neonates. Serial BIND score assessment and serial measurement of TSB and albumin could not be done. Sometimes, there was some delay in performing exchange transfusion because of unavailability of needed blood group. Subtle neurological deficits could have been missed; MRI and auditory brain stem response were done only to babies having abnormal motor examination; they should have been done to all babies attending the 3 months follow up visits. Longterm follow up is needed since some neurological insults may present in school age. Further randomized controlled trials are needed to emphasize know on evidence basis whether the concurrent use of $\mathrm{B} / \mathrm{A}$ ratio with $\mathrm{TSB}$ in the management of hyperbilirubinemia is of value or not needed.

\section{Conclusion}

$\mathrm{B} / \mathrm{A}$ ratio is a strong indicator for the risk of kernicterus. $\mathrm{B} / \mathrm{A}$ is more specific than TSB and should be used in the early management of neonatal hyperbilirubinemia.

\section{Abbreviations}

AAP: American Academy of Pediatrics; ABE: Acute bilirubin encephalopathy; ABR: Auditory brainstem response; B/A: Bilirubin to albumin ratio; Bf: Free bilirubin; BIND: Bilirubin-induced neurologic dysfunction; TSF: Total serum bilirubin; ROC: Receiver operating characteristic; $\mathrm{RH}$ : Rhesus; BAER: Brain stem auditory evoked response

\section{Acknowledgements}

Not applicable.

\section{Authors' contributions}

RS participated in the plan, trained EA for BIND examination and followed up the study, formulated and tabulated data, participated in the initial analysis, and wrote the initial and edited drafts; MK participated in the study plan, data monitoring and initial data analysis, supervised the final statistical analysis, and wrote the statistics section and reviewed and edited the manuscript; EA monitored results and reviewed and edited drafts; performed data acquisition and the BIND examinations on most subjects as part of a Master thesis; and IF initiated the project idea edited initial drafts and recommended approaches to analyzing and presenting data and collated the final draft in consultation with all coauthors. The authors read and approved the final manuscript.

\section{Funding}

No external funding was received by any of the authors for this work.

\section{Availability of data and materials}

The datasets used and/or analyzed during the current study are available from the corresponding author on responsible request.

\section{Ethics approval and consent to participate}

Ethics Committee, Pediatric Department, Cairo University. Ethics committee reference number was not available at the time this work was done. A written informed consent was taken from the parents of the study participants.

\section{Consent for publication}

Not applicable.

\section{Competing interests}

The authors declare that they have no competing interests.

Received: 25 July 2020 Accepted: 1 January 2021

Published online: 01 February 2021

\section{References}

1. Olusanya BO, Ogunlesi TA, Kumar P, Boo NY, Iskander IF, de Almeida MF et al (2015) Management of late preterm and term infants with hyperbilirubinaemia in resource-constrained settings. BMC Pediatr 15:39

2. Johnson L, Bhutani VK (2011) The clinical syndrome of bilirubin-induced neurologic dysfunction. Semin Perinatol. 35(3):101-113

3. Van Praagh R (1961) Diagnosis of kernicterus in the neonatal period. Pediatrics 28:870-876

4. Volpe JJ (2001) Bilirubin and brain injury. In: Neurology of the newborn, 4th edn. WB Saunders, Philadelphia (PA), pp 521-546 
5. Johnson L, Brown AK, Bhutani VK (1999) BIND—a clinical score for bilirubin induced neurologic dysfunction. Pediatrics 104(746):7

6. Johnson L, Bhutani VK, Karp K, Sivieri EM, Shapiro SM (2009) Clinical report from the Pilot USA Kernicterus Registry (1992 to 2004). J Perinatol 29(Suppl 1):S 25-S 45

7. American Academy of Pediatrics Subcommittee on Hyperbilirubinemia (2004) Management of hyperbilirubinemia in the newborn infant35 or more weeks of gestation. Pediatrics 114:297-316

8. Calligaris SD, Bellarosa C, Giraudi P et al (2007) Cytotoxicity is predicted by unbound and not total bilirubin concentration. Pediatr Res 62:576-580

9. Amin SB, Ahlfors C, Orlando MS et al (2001) Bilirubin and serial auditory brainstem responses in premature infants. Pediatrics 107:664-670

10. Hulzbos CV, Dijk PH, van Imhoff DE et al (2014) BARTrial study group. The bilirubin albumin ration in the management of hyperbilirubinemia in preterm infants to improve neurodevelopmental outcome: a randomized controlled trial - BARTrial. PLoS One 9(6):e99466

11. Iskander I, Gamaleldin R, El Houchi S, EL Shenawy A, Seoud I, El Gharbawi N et al (2014) Serum bilirubin and bilirubin/albumin ratio as predictors of bilirubin encephalopathy. Pediatrics 134(e):1330-1339

12. El Houchi SZ, Iskander I, Gamal el Din R, El Shenawy A, Seoud I et al (2017) Prediction of 3- to 5-month outcomes from signs of acute bilirubin toxicity in newborn infants. J Pediatr 183:51-55

13. van Imhoff DE, Dijk PH, Weykamp CW, Cobbaert CM, Hulzebos CV et al (2011) Measurements of neonatal bilirubin and albumin concentrations: A need for improvement and quality control. Eur J Pediatr 170:977-982

14. Shapiro SM (2010) Chronic bilirubin encephalopathy: diagnosis and outcome. Semin Fetal and Neonatal Med 15:157-163

15. Sing T, Sander O, Beerenwinkel N, Lengauer T. (2009) ROCR: Visualizing the performance of scoring classifiers. http://CRAN.R-project.org/package=ROCR [R package version 1.0-4]

16. Sgro M, Campbell D, Barozzino T, Shah V (2011) Acute neurological findings in a national cohort of neonates with severe neonatal hyperbilirubinemia. J Perinatol. 31(6):392-396

17. Gamaleldin R, Iskander I, Seoud I et al (2011) Risk factors for neurotoxicity in newborns with severe neonatal hyperbilirubinemia. Pediatrics 128(4) Available at: www.pediatrics.org/cgi/content/full128/4/e025

18. Mukhopadhyay K, Chowdhary G, Singh P, Kumar P, Narang A (2010) Neurodevelopmental outcome of acute bilirubin encephalopathy. J Trop Pediatr. 56(5):333-336

19. Smits-Wintjens VE, Rath ME, van Zwet EW et al (2013) Neonatal morbidity after exchange transfusion for red cell alloimmune hemolytic disease. Neonatology. 103(2):141-147

20. Oh W, Stevenson DK, Tyson JE, Morris BH, Ahlfors CE et al (2010) Influence of clinical status on the association between plasma total and unbound bilirubin and death or adverse neurodevelopmental outcome in extremely low birth weight infants. Acta Paediatr 99:673-678

21. Ahlfors CE, Wennberg RP, Ostrow JD, Tiribelli C (2009) Unbound (free) bilirubin: improving the paradigm for evaluating neonatal jaundice. Clin Chem. 55(7):1288-1299

22. Hulzebos CV, van Imhoff DE, Bos AF, Ahlfors CE, Verkade HJ, Dijk PH (2008) Usefulness of the bilirubin/ albumin ratio for predicting bilirubin-induced neurotoxicity in premature infants. Arch Dis Child Fetal Neonatal ED. 93(5): F384-F388

23. Moll M, Goelz R, Naegele T, Wilke M, Poets CF (2011) Are recommended phototherapy thresholds safe enough for extremely low birth weight infants? A report on two ELBW infants with kernicterus despite only moderate hyperbilirubinemia. Neonatology 99:90-94

24. Govaert $P$, Lequin $M$, Swarte R et al (2003) Changes in gllobus pallidus with preterm kernicterus. Pediatrics 112(6 Pt 1):1256-1263

25. Odutolu Y, Emmerson AJ (2013) Low bilirubin kernicterus with sepsis and hypoalbuminaemia. BMJ Case Reports. https://doi.org/10.1136/bcr-2012008042

26. Maisels MJ, Watchko JF (2003) Treatment of jaundice in low birthweight infants. Arch Dis Child Fetal Neonatal Ed 88:F459-F463

27. Blackmon LR, Fanaroff AA, Raju TN (2004) Research on prevention of bilirubin-induced brain injury and kernicterus: National Institute of Child Health and Human Development conference executive summary. 2003. Pediatrics 114:229-233

28. Ardakani SB, Dana VG, Ziaee V, Ashtiani M-TH, Djavid GE, Alijani M (2011) Bilirubin/albumin ratio for predicting acute bilirubin-induced neurologic dysfunction. Iran J Pediatr. 21(1):28-32
29. ElTatawy SS, Elmazzahy E, El Shennawy A, Madani H, Abou Youssef H, Iskander I (2019) The spectrum of bilirubin neurotoxicity in term and near term babies with hyperbilirubinemia: Does outcome improve with time. Early Hum Dev 140:104909

\section{Publisher's Note}

Springer Nature remains neutral with regard to jurisdictional claims in published maps and institutional affiliations.

\section{Submit your manuscript to a SpringerOpen ${ }^{\circ}$ journal and benefit from:}

- Convenient online submission

- Rigorous peer review

- Open access: articles freely available online

- High visibility within the field

- Retaining the copyright to your article

Submit your next manuscript at $\boldsymbol{\nabla}$ springeropen.com 